\title{
The effects of performance feedback, social and monetary incentive upon human lever pressing rate'
}

PAUL G. SWINGLE, HENRY COADY AND DONALD MOORS

DALHOUSIE UNIVERSITY

Ss lever pressed on FR 10 for points. Points were given reinforcing properties by $E^{\prime} s$ instruction. Results indicated no difference in variability or response rate for monetary or social reinforcement but large differences in variability for self competition. An incentive decrement effect hypothesis is discussed.

There is an increasing amount of evidence which is suggesting that the effect of incentive is that of reducing between-subject variability. Data from several studies, particularly child studies, lead one to consider the possibility that the incentive does not reduce variability only by increasing the rate of low responders but also by decreasing the rate of high responders. Terrell (1958), for example, found that in a group of intrinsically motivated children, discrimination learning was best under conditions of performance feedback and poorest under conditions of added incentive. These results were directly opposed to an earlier study (Terrell \& Kennedy, 1957) in which lower socioeconomic class children, and presumably less highly self-motivated, were used.

Other data from child studies may also be interpreted in terms of an incentive decrement effect. Stevenson and Hoving (1964), for example, found that nursery school children made more correct responses in a probability matching situation under low incentive (a washer) than under high incentive (a nickel). Miller \& Estes (1961) report similar results-fewer errors with performance feedback relative to monetary reward.

Although discrimination learning is not the best experimental situation for determining incentive decrement effects because of the uncontrollable effects different incentive conditions may have upon interfering responses, the above results are in agreement with findings in lever pulling situations. Ryan \& Moffitt (1965) found that faster speeds were obtained when children were lever pulling for a low incentive (a piece of string) than for a high incentive (a ten cent toy). This was in general agreement with Bruning's (1964) finding of a slight (non-significant) decrement in children's lever pulling speed for a large incentive (five pieces of candy) relative to the speed obtained for a smaller incentive (one piece of candy).

The present study compared the effectiveness of several quite different incentive conditions with a performance feedback control in maintaining simple lever pressing behavior.

\section{Method}

Ss were seated in a ventilated sound resistant cubicle about $4.5 \mathrm{ft}$. by $5 \mathrm{ft}$. in size. The cubicle contained a standard $19 \mathrm{in}$. by $21 \mathrm{in.} \mathrm{table} \mathrm{model} \mathrm{relay} \mathrm{rack} \mathrm{on}$ which a light, an electric impulse counter and a Stromberg-Carlson cam key (No. 171D) were mounted.

The experimental session consisted of 45, 20-second periods indicated by light onset on the S's panel, during which time the $\mathrm{S}$ could accumlate points shown on his counter in a ratio of 1 point for every 10 lever presses (FR 10). Stimulus presentations, reinforcement points, recording of lever pressing responses, etc., were accomplished by means of standard programming and recording apparatus.

Once seated in front of the response panel, the $S$ heard the instructions over an intercom system. All Ss were informed that the study was concerned with "motor activity" and that they could accumulate points as shown on their counters if they pushed the lever rapidly whenever their panel light was on and that the faster they manipulated the lever the more points they would receive.

Five groups of 6 male students registered in the introductory psychology course at Dalhousie University constituted the sample. Each S, regardless of his assigned experimental group, received identical instructions save for the last sentence, which established the reinforcing significance of the accumulated points. The conditions were as follows:

Self competition (SeC) - "Try to accumulate as many points as possible."

Class norm (CN)-"Most males in your class obtain about 450 points or about 10 per trial; try to accumulate as many points as possible."

Social competition (SoC)-'YYou are competing against 5 other persons;..."

Social competition for monetary reward (SCM) -

Table 1. Average number of responses per second and range of response rates for the last ten trials in each condition

\begin{tabular}{lccc} 
Condition & $\begin{array}{c}\text { Mean No. } \\
\text { of Responses } \\
\text { Per Second }\end{array}$ & \multicolumn{2}{c}{$\begin{array}{c}\text { Range } \\
\text { Fastest S }\end{array}$} \\
\hline SeC & 5.8 & 9.4 & $\begin{array}{c}\text { Per of Responses } \\
\text { Pecond } \\
\text { Slowest S }\end{array}$ \\
CN & 6.8 & 7.8 & 2.4 \\
SoC & 6.4 & 7.8 & 4.1 \\
SCM & 6.2 & 7.2 & 5.0 \\
M & 6.1 & 7.2 & 5.0 \\
\hline
\end{tabular}


'You are competing against 5 other persons for $\$ 2.50 ; \ldots$.

Monetary reward $(M)-" Y o u$ will receive 16 for every 5 points you accumulate;..."

\section{Results}

Table 1 shows the average number of responses per second and the range (i.e., fastest and slowest subject means) during the last ten trials for each condition. As indicated by the range, there is considerable variability in the SeC group relative to the other conditions.

Considerably less variability may be observed in the last ten trials of conditions $\mathrm{CN}$, SoC, SCM and M. A Cochran's C test for homogeneity of variance (Winer, 1962) indicated a significant departure from homogeneity between the five groups $(\mathrm{C}=.625, \mathrm{p}<.01)$. A Cochran's test on groups $\mathrm{CN}$, SoC, SCM and M indicated no significant difference in variability $(\mathrm{C}=.281, \mathrm{p}<.05)$ which indicates that the self competition condition results in a population which has a markedly different variance from the social or monetary conditions.

The average number of responses per second over the course of the experimental session for each group is shown in Fig. 1. The SeC group was divided in half so that the mean for the three fastest responders and the three slowest responders are plotted separately. This arbitrary separation shows quite well the striking difference between fast and slow responders in the performance feedback (SeC) condition.

The four incentive plus performance feedback conditions all have similar response curves. An analysis of variance on the last 10 trial data for these four groups indicated no significant differences $(F<1.00)$.

\section{Discussion}

The results indicate that social competition is as effective as a small monetary reward in terms of

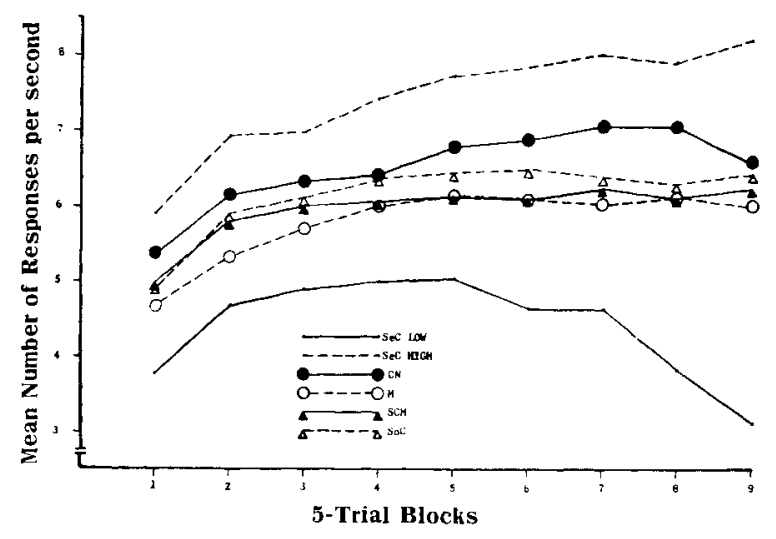

Fig. 1. Average number of responses per second for all groups as a function of 9 blocks of 5 trials per block. The three fastest and the three slowest $\mathrm{Ss}$ in group $\mathrm{SeC}$ are plotted separately. maintaining lever pressing and yielding a homogeneous population variance. Of particular interest is the marked heterogeneity observed in the self competition condition where some Ss demonstrate very low response rates (e.g., 2.4 responses per second) while others evoke exceedingly high response rates (e.g., 9.4 responses per second) which, for some $\mathrm{Ss}$, show little indication of asymptote after 45 trials. It is quite likely that, for some Ss, self competition may be a natural concomitant of performance feedback situations and a very effective motivator and that the effect of additional motivating contingencies (i.e., money or social competition) may be that of actually inhibiting maximum response rate. For other Ss less responsive to the self competitive situation, social or monetary reinforcers may be necessary to maintain behavior.

Finally, although some authors have attempted to explain unexpected results in terms of a frustration or a similar state theory, a consideration of Fig. 1 suggests hypotheses based upon an incentive decrement effect notion which might explain the inconsistencies in the literature. The often reported finding of performance feedback being superior, in terms of some performance measure, to performance feedback plus incentive is accounted for by the decremental effect of incentive upon intrinsically motivated subjects. The many "no difference" results would be obtained if a sample of highly and poorly motivated Ss were used and their response rates averaged. If poorly motivated Ss were used (e.g॰ lower class children), incentive effects would be obtained.

The hypotheses derived from these preliminary data required within-subject designs for adequate test. Studies of this nature are in progress.

\section{References}

Bruning, J. L. The effects oi magnitude of reward and percentage of reinforcement on a lever movement response. Child Develpm., 1964, 35, 281-286.

Miller, L. B., \& Estes, B. W. Monetary reward and motivation in discrimination learning. J. exp. Psychol., 1961, 61, 501-504.

Ryan, T. J., \& Moffitt, A. R. Response speed as a function of age, incentive value, and reinforcement schedule. Child Develpm., in press.

Stevenson, H. W., \& Hoving, K. L. Probability learning as a function of age and incentive. $J$. exp. child Psychol, 1964, 1, 64-70.

Terrell, G. The rite of incentive in discrimination learning in children. Child bevelpm., 1958, 29, 231-236.

Terrell, G., \& Kennedy, W. A. Discrimination learning and transposition in children as a function of the nature of the reward. J. exp. Psychol., 1957, 53, 257-260.

Winer, B. J. Statistical Principles in Experimental Design. New York: McGraw-Hill, 1962.

\section{Note}

1. This study was supported by Grant APA-158, National Research Council of Canada and a Dalhousie University Research Grant to the first author. 